\title{
Lengua y mercado en el mundo hispanohablante: un acercamiento al estado de la traducción literaria
}

\author{
Laura Calabrese Steimberg \\ Université Libre de Bruxelles
}

This paper analyzes the status of literary translation in Spanish America and its conditions of production. Working with the Argentinean case as an example, we try to explain the logic of a cultural field strongly shaped by editorial globalization and economic dependency on the former home country. We discuss a number of theoretical issues related to the possible existence of a mega-polysystem linking the Spanish-speaking countries and their literary systems, as a way to approach the complex relations between a supraregional language and the national States sharing it. In this context, we analyze the unequal distribution of Spanish dialectal variations in the verbal market, and we examine the strategies that aim at resisting this kind of cultural dependency.

\section{Presentación de la problemática}

Resulta evidente, a primera vista, que hablar del estado de la traducción literaria en cualquier región lingüística implica disponer de un balance, que en el caso que nos ocupa nunca ha sido realizado. Sólo contamos con síntomas, que nos permiten articular intuiciones provenientes del saber común con una serie de conceptos teóricos bien desarrollados, que tomaremos de la teoría del polisistema.

Por otro lado, hablar del mundo hispanohablante implica pensar diversos sistemas autónomos como uno, o cuando menos pensar un sistema culturalmente diverso en términos de unidad lingüística. Si queremos analizar el estado de la traducción literaria en una región lingüística desde una perspectiva sistémica, resulta imprescindible intentar definirla, tratando de cernir el alcance de las transacciones editoriales, culturales - en suma, económicas - , entre varios sistemas que se perciben como autónomos pero cuyas interacciones no pueden ignorarse. Para ello deberemos sobreponernos a dos evidencias que pueden ocultar el verdadero estado de la cuestión: por un lado, la geográfica e histórica, que nos empujaría a definir un polisistema hispanoamericano y uno español autónomos, haciendo caso omiso de la lengua suprarregional; por el otro, la evidencia lingüística, que puede hacernos pensar en un sistema panhispánico sin tensiones, por ende sin relaciones estructurales reales. Recordemos que para Even-Zohar (1990a: 12) el término 'polisistema' tiene por objeto poner de manifiesto la naturaleza dinámica y heterogénea de un sistema, entendido como un conjunto cerrado de relaciones y al mismo tiempo como una estructura abierta consistente en muchas de estas redes de relaciones concomitantes ${ }^{1}$. 
Lo fundamental es preguntarse si las problemáticas que recorren la traducción literaria en Hispanoamérica constituyen un mero síntoma de colonialismo cultural y económico o si responden más bien a las relaciones estructurales entre el sistema literario hispanoamericano y el español. La literatura latinoamericana es una realidad editorial, económica y simbólica modelada por el mercado (el internacional como el local), pero también por géneros, poéticas y búsquedas comunes. Haciendo un recorte aún más regional, podemos definir una literatura hispanoamericana, subrayando una matriz geográfico-lingüística incuestionable. Sin embargo, resulta más difícil referirnos a una literatura panhispánica como un conjunto sistemático. Se habla de literatura hispanoamericana en un sentido muy distinto del que se habla de literatura europea, ya que se está haciendo hincapié en una unidad histórico-geográfica pero sobre todo linguiística. En suma, si al hablar de regiones lingüísticas estamos asumiendo que la lengua es un factor de unificación literaria, sabemos que no es el único para definir la existencia de un polisistema, con lo cual quedarían por probar las relaciones estructurales reales que lo constituyen.

Pensamos que al interrogar la geografía del sistema podremos observar ciertas relaciones estructurales - principalmente de oposición, pero no únicamente - entre distintos campos literarios que viven en situación de interferencia constante, lo que nos permitiría explicar el estado en el que se encuentra la traducción literaria en América hispanohablante. Para ello tomaremos el ejemplo argentino, ya que se trata de uno de los campos literarios que más fuertemente se han estructurado en torno de la traducción de textos extranjeros (desde el proyecto de la generación de 1837 hasta su auge con las traducciones de la revista Sur), y porque su caída como polo cultural regional resulta ejemplar. Para terminar expondremos lo que nos parece ser una de las estrategias de resistencia cultural a la dominación editorial peninsular en la región, tratando así de verificar las oposiciones estructurales entre los dos sistemas.

Pensando las literaturas regionales como polisistemas (es decir, teniendo en cuenta no sólo el capital literario de un país o región sino las relaciones culturales en las que están inmersos), intentaremos analizar y explicar la lógica de la recepción pasiva de traducciones.

\section{Polisistemas de recepción pasivos}

A pesar de la falta de datos sistemáticos, se sabe que la mayoría de los textos literarios traducidos que ingresan en el mercado hispanoamericano son hechos en España. Las causas de esta situación se encuentran en la concentración editorial que se ha producido a partir de la década de 1990, y que ha dado como resultado el relegamiento de antiguos focos culturales regionales (productores de traducciones, publicaciones y premios consagratorios) y la reestructuración del sistema literario regional. Las viejas 'capitales culturales' hispanoamericanas ${ }^{2}$, es decir aquellas que revindican la autonomía li- 
teraria y administran el capital intelectual regional (Casanova 2001), como Buenos Aires o México, han perdido buena parte de su protagonismo en la escena cultural y asistido al desmantelamiento de sus redes productivas (principalmente editoriales, pero también universidades y medios de difusión independientes), sin dar lugar a nuevos polos culturales en la región. Una consecuencia directa de esta reestructuración es que las políticas de planeamiento cultural se han desplazado fuera del campo cultural receptor. De esta manera, no sólo la producción editorial local sino también la 'intraducción' (Minon \& Ganne 1992), es decir la importación de textos extranjeros mediante traducciones, se imponen con criterios externos al sistema. El alcance de esta reestructuración puede apreciarse en el descentramiento de las literaturas nacionales de acuerdo con las etiquetas de las editoriales globalizadas, que "fueron fragmentando el mercado del libro latinoamericano e inventaron las nuevas 'literaturas nacionales' que necesariamente debían integrar a sus catálogos. El ejemplo más acabado de ese proceso es la famosa Biblioteca del Sur, ideada en Buenos Aires [...] para Planeta"3 (Link 2001).

Desde una perspectiva sistémica como la que adoptamos, los dos fenómenos (la intraducción y la regulación de la producción nacional) forman parte de una problemática mayor que integra la cuestión de la traducción a la de la literatura y la cultura en general, lo que José Lambert (1989) ha subsumido bajo el concepto de 'mapas literarios y culturales', que nos permiten observar el proceso de regionalización de una literatura nacional. En el estado actual de las literaturas nacionales en Hispanoamérica, la constitución de estos mapas alcanza enorme complejidad en razón de la multiplicidad de lenguas amerindias (y del indiscutible clivaje entre literatura escrita y oral), aunque la posición de lengua literaria y editorial por excelencia del español no haya podido ser desplazada. Por lo tanto, la situación editorial de estos países se halla indisolublemente ligada a la de España (cuyo mapa lingüístico es un capítulo aparte), aunque no siempre en situación de dependencia, como veremos, si bien actualmente toma la forma de una dominación casi exclusivamente económica, lo cual evidentemente afecta la relativa autonomía del campo intelectual.

El problema, en lo que respecta a la importación de traducciones, es doble: por un lado, la imposición de la variante dialectal peninsular (en su versión estándar), que opera sobre el nivel de la recepción de las obras ${ }^{4}$, y por otro, la imposición de un canon extranjero con criterios externos, que opera sobre el planeamiento cultural propio a toda actividad editorial, y especialmente la traducción. En palabras del investigador Gideon Toury (en prensa), "It cannot be contested that, being norm-governed by its very nature, translation is as much a means of effecting planning as it is a paradigmatic case thereof'. Sobre el aspecto de la desigual distribución dialectal en la actividad traductora (tanto más evidente cuanto que se impone a un mercado hispanoamericano que tiene a su vez una laberíntica variedad dialectal), no es mucho lo que podemos agregar, dado que sus consecuencias en el nivel de la recepción sólo nos permiten emitir intuiciones, si bien es cierto que el fenómeno es a menudo evocado por escritores e intelectuales 
(ver nota 7), y a veces incluso permite interpretar el malestar como síntoma de una reestructuración mayor en el sistema de la cultura. Como explicaba hace ya una década el director editorial (argentino) del grupo editor AguilarAltea-Taurus-Alfaguara para ilustrar por qué no realizaba traducciones en Argentina ni modificaba las que llegaban de España: "Esta decisión tiene como objetivo preservar el castellano en su esencia. Cualquier lector argentino puede leer una novela española usando el diccionario" (Battista 1992). La declaración es elocuente: el imperativo económico debe ser justificado en el nivel del planeamiento cultural ("preservar el castellano"), incluso a riesgo de cometer un error conceptual en el ámbito de la más básica sociolingüística ("en su esencia").

En lo que respecta al segundo aspecto, es decir la intraducción planificada fuera del sistema literario receptor, resulta del mayor interés para el investigador, ya que se ubica en la intersección de varios problemas planteados por la teoría de la traducción. Recordemos que para G. Toury, que hace un especial hincapié en el papel de la traducción en la modelización del sistema receptor, la cultura es vista como un repertorio estructurado de opciones predeterminadas que organizan la interacción social. Desde este punto de vista, el planeamiento consiste en cualquier acto más o menos deliberado de intervención con respecto a estas opciones.

Si la actividad traductora consigue (y en general busca) producir cambios en el sistema receptor, como ya ha demostrado Even-Zohar (1990b), y si, como avanza Toury, la actividad traductora es una actividad teleológica cuyo éxito o fracaso se definen en términos de los requerimientos de la cultura meta, entonces podemos formular el problema que nos ocupa en estos términos: ¿qué sucede en el sistema receptor cuando importa sus traducciones de otro sistema con el cual comparte la lengua? Dado que la naturaleza del fenómeno, nos previene Even-Zohar, depende del estado de cada sistema, podemos reformular: ¿qué sucede cuando un sistema relativamente establecido, por ende relativamente independiente, se convierte en receptor pasivo de traducciones? 'Relativamente establecido' e 'independiente' significa que produce gran parte de los textos y del repertorio (modelos) que el mismo sistema demanda, y que tiene la capacidad de atraer y acoger aquellos de los cuales carece, especialmente por medio de la traducción. Tradicionalmente, el polisistema literario argentino (como el latinoamericano en general) es importador de géneros llamados de masas, principalmente ciencia ficción y policial. Sin embargo, este último género es un excelente campo para verificar la hipótesis de la traducción como planificación cultural, dado que su introducción en la literatura argentina ha sido el producto de sucesivos proyectos editoriales por parte de escritores y traductores reconocidos, que ha dado como resultado la reestructuración del polisistema, modificando las relaciones entre el canon y los textos/repertorios periféricos. El gran artífice de la revolución genérica en la Argentina del siglo XX, J. L. Borges, supo introducir, en su calidad de traductor (y como miembro de un proyecto de enorme alcance desarrollado por la revista Sur), el cuento fantástico y la novela y el cuento policial, que a su vez cultivó como escritor y 
promovió como editor (en la colección El séptimo círculo ${ }^{5}$ ). No es difícil comprobar que su posición dentro del campo literario argentino le permitió introducir aquellos géneros que 'necesitaba' para realizar su proyecto de escritor. A fines de los años sesenta, el escritor Ricardo Piglia realizó una operación similar, al introducir por medio de la colección Serie Negra toda una zona de policial negro que El séptimo círculo había dejado vacante, el hard boiled norteamericano surgido en los años treinta, género del cual se serviría para su propio proyecto de narrador. Estos dos escritores ejemplifican cómo la traducción puede contribuir al proyecto literario (y por ende forma parte del mismo sistema), haciendo desplazar un género 'menor' al canon, es decir de la periferia al centro del polisistema.

El problema se plantea entonces en un sistema que ha conseguido su autonomía relativa basándose fuertemente en la intraducción, por lo cual se puede prever que es también capaz de desarrollar estrategias de resistencia ante la nueva situación de dependencia y nuevos canales de selección de textos y de repertorios. Efectivamente, ante el bloqueo de la actividad editorial argentina, se puede observar cómo los suplementos literarios y culturales de la prensa asumen este papel, sobre todo los que se encuentran más cerca de las vanguardias literarias y académicas, por oposición a aquellos que apuestan más fuertemente a la reproducción de repertorios ya establecidos.

En un artículo intitulado "Literatures, Translation and (De)Colonization", Lambert (1995) aborda el problema de la importación de traducciones por parte de sistemas literarios periféricos que además comparten una lengua suprarregional con otro sistema, con el que mantienen relaciones de dependencia. El planteamiento del problema en el marco de una teoría dinámica de la cultura lo lleva a concebir la traducción, al igual que Toury, como una serie de estrategias regidas por determinados criterios de selección y no selección (de textos y de principios textuales). Como hemos visto, el estado actual del sistema editorial hispanoamericano en general no está en condiciones (salvo apertura de nuevos canales y estrategias de resistencia, como veremos) de intervenir en este proceso, con lo cual ve bloquearse uno de los medios más efectivos para renovar tanto su capital literario como los modelos según los cuales se traduce. Por ende, tampoco va a ser capaz de modificar las normas de traducción, como sería el caso si el sistema tuviera la capacidad de regular la demanda según sus necesidades.

Intentando formular algunas reglas básicas de importación/exportación del intercambio entre sistemas culturales, Lambert avanza una serie de hipótesis, tres de las cuales ayudan a pensar la situación que describimos:

- cuanto más importa una sociedad determinada de un mismo sistema vecino, más se acrecienta su posición de dependencia;

- cuanto más cercano en el espacio y el tiempo se encuentre ese sistema vecino, más posibilidades hay de que absorba global o parcialmente al sistema importador; 
- cuanto más pertenezca el sistema receptor a un grupo de sistemas receptores que importan sus productos culturales del mismo sistema exportador, más subordinado se encontrará a una red coherente y a (una jerarquía de) otros sistemas meta más débiles.

Sin embargo, la importancia de determinar el grado de dependencia cultural de una sociedad con respecto a otra (es decir, su posicionamiento en un sistema jerárquico) no podría ser definida en términos absolutos, en razón de la definición misma de polisistema, que hace de la interdependencia entre sus componentes la condición de posibilidad de su existencia, tanto en lo que respecta a las relaciones intra como a las intersistémicas, lo que Even-Zohar denomina las leyes de interferencia literaria (1990c).

Lo que nos ofrece la posibilidad de enunciar esta dependencia en términos relativos son las estrategias que surgen en una sociedad para resistir a esa dominación, o mejor dicho, estas estrategias, leídas como síntoma, son las que nos revelan la situación de dependencia. De otro modo, ¿qué nos permitiría suponer que el estado actual de la traducción literaria en el sistema literario argentino, e hispanoamericano en general, es el producto de una dependencia y no el signo de una peculiar red de relaciones entre el sistema hispanoamericano y el español, que constituirían así una suerte de megapolisistema?

\section{2. ¿Existe un sistema panhispánico?}

En las últimas décadas, muchos investigadores (Bein 2001; Casanova 2001; Lambert 1989) han puesto en duda la pertinencia de tomar el esquema de las literaturas nacionales como el único posible, no sólo porque dicho modelo resulta ya anacrónico, sino porque impide pensar las interdependencias y los desplazamientos entre sistemas. Evidentemente, es la noción misma de sistema literario lo que está en juego aquí y los criterios que intervienen en su definición, ya sea la lengua, un canon textual o, siguiendo la versión dinámica de la teoría del polisistema, una serie de relaciones estructurales y estructurantes. La problemática puede enunciarse con ayuda del concepto de mapas literarios desarrollado por Lambert. Si bien su apuesta central es denunciar la concepción imperante de literatura, que excluye de su ámbito una serie de géneros y de manifestaciones literarias (los relatos orales, el teatro y la literatura de masas), la idea general que se desprende es la impugnación de la equivalencia una nación/una lengua/una literatura, en razón de la coexistencia de varias tradiciones literarias en el seno de un espacio sociocultural. En este sentido, el mapa literario hispanoamericano debería incluir una zona de contacto importante con el sistema español, que a su vez forma parte de un megasistema mayor, el de la literatura europea. Dejando de lado tamaña ambición por el momento, podemos limitarnos a una zona reducida de ese mapa, sin tomarla como una muestra en pequeña escala de la situación global, e intentar cernir las relaciones estructurales que mantiene con el sistema del cual importa sus traducciones. 
Si abordamos el proceso de autonomización del campo literario argentino desde una perspectiva sistémica, resulta evidente que tenemos que salir de los límites circunscritos del espacio nacional, ya que el proceso es incomprensible si no enfocamos la clara rivalidad con España, su lengua y sus instituciones literarias. Según la crítica francesa Pascale Casanova, toda literatura nacional surge de un primer estadio de acumulación de capital literario, a partir de la rivalidad fundacional con otra literatura o lengua, y no a partir de la continuidad de la influencia extranjera. En Argentina, "ese larguísimo proceso histórico, en el curso del cual se conquista la autonomía y se constituye el fondo literario [...], le permite a la literatura liberarse del tiempo y pensarse a sí misma como una práctica que escaparía a la historia" (Casanova 2001: 120), comienza con la generación del 37 en el siglo XIX y alcanza su culminación con la obra de J. L. Borges, con quien la problemática adquiere sus condiciones de máxima visibilidad en el campo literario argentino ya constituido. No es difícil ver una continuidad entre el proyecto del primer Borges y las ideas de la generación romántica del 37. Esta última, influenciada por los escritos de Herder, propone la creación de una lengua nueva para la nueva nación ${ }^{6}$, proyecto que construirá alrededor de las lecturas y la traducción de los autores que representan 'los pueblos adelantados de Europa' (especialmente Francia). Si la generación romántica propone un modelo fuertemente anclado en lo que Fishman (1972) denomina "the holy trinity" (holy people, holy land, holy language) ${ }^{7}$, el proyecto de Borges, alejado de la triple equivalencia dictada por el nacionalismo lingüístico, terminará de postular aquel objeto sobre el que funda buena parte de su obra ensayística: el idioma de los argentinos ${ }^{8}$. Este breve guiño a la historia literaria argentina nos recuerda hasta qué punto este sistema literario se constituye alrededor de una 'lengua' propia, en clara actitud rupturista con el español peninsular, pero al mismo tiempo a partir de la interferencia con las literaturas europeas por medio de la traducción.

Borges termina de cerrar la antigua polémica entre casticistas y criollistas y funda la posibilidad de un sistema literario autónomo (que no tenga como referente a la antigua metrópolis), que debe mucho a la posición que su obra ocupará dentro del canon occidental. En un gesto de deliberado anacronismo borgeano, podríamos decir que es él quien funda la tradición literaria argentina, no sólo porque opera una reorganización del canon nacional que aún tiene vigencia, sino porque la posición que su obra ocupa en el canon occidental es lo que permite percibir la literatura argentina como un conjunto coherente y autónomo desde las literaturas centrales. De la misma manera, este posicionamiento es el que permite la legitimación de una lengua literaria local a través de su ingreso en el sistema literario español, realizando un importante movimiento a favor de una estandarización policéntrica del castellano9. Cabe decir que ésta ha sido una preocupación común de los escritores latinoamericanos en el siglo $\mathrm{XX}$, y que no podemos, por ende, subestimar la búsqueda de una lengua literaria local como uno de los medios de construir una tradición propia, como sugiere Casanova al decir que, puesto que "la lengua no era un elemento que dife- 
renciase [a los pioneros criollos] de sus metrópolis respectivas", las literaturas americanas son herederas directas de las naciones europeas de las que proceden, y que "los escritores de esas regiones se apropiaron, en una especie de continuidad patrimonial, de los bienes literarios y lingüísticos de los países europeos cuyo legado reivindican" (2001: 118-119) ${ }^{10}$.

Ahora bien, el momento en que las literaturas hispanoamericanas penetran en el sistema europeo (que tiene su auge con la denominada literatura del boom) pone de manifiesto una situación ambigua: por un lado, atestigua el movimiento de autonomización y el comienzo de la estandarización policéntrica del castellano, y por el otro afirma los medios de consagración de los sistemas centrales. Sin embargo, no podemos ignorar que este proceso de canonización modifica la configuración del sistema literario español, y por ende la fisonomía del intercambio editorial. Dicho de otro modo, parecería que a medida que estos sistemas periféricos ganan autonomía, otro tipo de interferencia parece posible entre ellos, y la metrópoli pasa a ser definida como un 'socio privilegiado' del intercambio cultural más que como una fuente de modelos literarios.

Intentando evitar la perspectiva textocentrista contra la que nos previene Even-Zohar, podemos decir, a favor de la tesis de un megapolisistema panhispánico, que los diversos sistemas literarios comparten no sólo textos canónicos sino relaciones que podríamos suponer estructurales y no coyunturales. Evidentemente, el factor lingüístico, a pesar de no ser el único, es un elemento cohesivo mayor del megapolisistema, lo cual explica también la configuración jerárquica del 'mercado verbal' (Casanova 2001) que conforman España e Hispanoamérica. Así, cuando Octavio Paz declara en su discurso de recepción del Nobel: "Mis clásicos son los de mi lengua, y me siento descendiente de Lope y de Quevedo como cualquier escritor [...] pero no soy español" (1994: 31), no hay que olvidar que, como en el caso de Borges, es su posición central en el canon occidental lo que le permite refundar una literatura que es ante todo nacional.

Una historia comparada de los sistemas literarios en español mostraría cómo los repertorios de uno y otro se han renovado por interferencias mutuas, y tal vez más fácilmente en la periferia del canon, como es el caso de la novela policial, cuya traducción y publicación asumieron en buena medida editoriales españolas a mediados de los años setenta, operando en un espacio que había sido abierto por editoriales argentinas. Además, basta con pensar en el papel que jugaron las redes editoriales latinoamericanas y españolas para difundir textos (y por ende modelos) en momentos de crisis política. Así, la lógica del mundo literario permitió a los intelectuales de la España de la posguerra leer libros editados en Buenos Aires y México, respondiendo a una demanda del sistema literario, que había perdido su autonomía para convertirse en polo heterónomo del poder político, como cuenta el escritor español Juan Benet:

La metamorfosis de Kafka había sido traducida justo antes de la guerra, un volumen muy pequeño que pasó casi inadvertido. Pero nadie conocía las 
grandes novelas de Kafka; había que comprarlas en ediciones sudamericanas [...] Ningún escritor había sufrido la influencia de los grandes escritores de este siglo. Era casi imposible conocer esos libros que procedían del extranjero; no estaban prohibidos, pero sencillamente no existía la importación de libros. (entrevista inédita, en Casanova 2001: 146-147)

Lo interesante de esta cita es que pone de manifiesto el comportamiento de un sistema literario en crisis, que exige un repertorio con el cual no cuenta y que debe dirigirse a otros sistemas para suplir la falta de traducciones, medio privilegiado para la renovación de modelos y del canon textual.

De esta manera, vemos cómo el polisistema literario hispanoamericano interfiere con el español, que no cuenta con los medios para autorregular su demanda. Esta misma lógica puede aplicarse para leer la literatura en el exilio (tanto hispanoamericana como española), que ha funcionado en diversos momentos como un espacio intermedio entre los dos sistemas.

Actualmente, el circuito de producción y distribución de las traducciones tal como funciona entre España e Hispanoamérica pone en duda esta versión de un sistema panhispánico capaz de poner en marcha mecanismos de autorregulación, y esto por dos motivos:

- porque la globalización editorial ha iniciado un proceso de regionalización de las literaturas hispanoamericanas, extrayendo una serie de sistemas nacionales de su contexto real de producción;

- porque la producción de traducciones en el sistema español no puede satisfacer la demanda de los sistemas literarios hispanoamericanos, que sin embargo están en condiciones de desarrollar ciertas estrategias de resistencia.

\section{Retraducir a Shakespeare: un proyecto panhispánico}

En los últimos veinte años, el sistema literario argentino ha experimentado una renovación importante de su repertorio, incorporando géneros antes inexistentes por medio de la traducción, especialmente el policial y la novela histórica, pero también la ciencia ficción y la llamada literatura femeni$\mathrm{na}^{11}$. A pesar de que la traducción literaria parece haber abandonado el centro de la escena que ocupó en la época de gloria del proyecto Sur, el sistema atraviesa una crisis sin precedentes que parece exigir una nueva renovación, a la cual la traducción no es ajena. En este marco han surgido una serie de emprendimientos editoriales locales con una política común, atentos a un mercado que las grandes empresas globalizadas no satisfacen: publicación de autores noveles, reediciones de obras agotadas y retraducciones. Lo interesante es hasta qué punto la traducción puede constituir un medio de renovación, no ya de repertorios o de textos sino de normas de traducción, en un mercado que se caracteriza casi enteramente por la importación pasiva. Esta situación se explica por el doble posicionamiento del polisistema li- 
terario argentino: periférico con respecto a España, central con respecto a Hispanoamérica, lo cual le permite señalar los espacios de vacancia en el sistema regional e intentar frenar el avance del monocentrismo.

El proyecto que más llama la atención es sin duda 'Shakespeare por escritores', una empresa concebida en Argentina a fines de los años noventa y distribuida por la editorial colombiana Norma que tiene el propósito de producir un Shakespeare panhispánico, con traductores que abarquen un amplio abanico de las variantes dialectales del castellano. El emprendimiento tiene un obstáculo obvio: la falta de unidad estilística y dialectal (cada texto está a cargo de uno o más traductores de un país diferente), aunque este escollo es también el punto fuerte de una ambiciosa apuesta que no ignora la lógica de los 'mercados verbales'. Como explica el editor general, Marcelo Cohen, "la relación de Latinoamérica con la tradición está a punto de colapsar, y de lo que se trata es de establecer quién es el dueño de la lengua" (Gamerro 2000). En tanto gesto que se propone perturbar abiertamente los códigos implícitos del mercado de las traducciones en Hispanoamérica, es importante notar que los traductores son todos narradores, poetas o dramaturgos. El proyecto parte del postulado de que son los escritores los que reelaboran el material literario disponible, lo que no deja de recordar las bases del proyecto Sur, y nos dice en qué medida la traducción literaria sigue ocupando una posición primaria cuando se trata de obras que ocupan el centro del polisistema. Se trata entonces de crear las condiciones de producción necesarias para que los escritores locales puedan apropiarse de un material extranjero sobre el cual recaía una especie de regla implícita: los clásicos se traducen en España. El gesto es circular y doble: al traducir se relee en la propia lengua, al releer en la propia lengua se reincorpora al clásico al sistema local, que aquí es claramente un sistema panhispánico.

El canon shakespeareano, el clásico por excelencia, ingresa una vez más en un sistema literario cuya existencia se había vuelto dudosa pero que se reconstruye en la traducción. Como explica Carlos Gamerro, escritor y traductor argentino, al reseñar el proyecto, hay en esa empresa:

[...] una tozudez casi bolivariana o guevarista de avivar el alicaído fantasma de esa entelequia llamada alguna vez literatura latinoamericana, hoy en día atomizada, o representada por literaturas que se vinculan radialmente a partir de la edición y la distribución españolas, y no de manera horizontal y entrecruzada. (Gamerro 2000)

De esta manera, el proyecto intenta crear - admitiendo en el gesto mismo su existencia - una zona cultural que permita nuevas condiciones de producción en el mercado panhispánico de los bienes simbólicos. Además, pone de manifiesto la movilidad y la autonomía del espacio literario, capaz de explicitar su lógica jerárquica y de actuar sobre esta jerarquía al tiempo que se la enuncia. Sin embargo, la autonomía misma del sistema literario impide pensar que este tipo de estrategias pueda actuar fuera del campo, en un polo económico que dicta cada vez más la forma de los mapas culturales y la con- 
figuración de las literaturas regionales (y regionalizadas). A pesar de esta perspectiva, es posible que, en la medida en que una zona del espacio literario se vuelve cada vez más heterónoma del polo económico, ese proceso no haga más que acelerar la autonomía de otra zona en la que la lucha por el poder simbólico que movilizan la lengua y los bienes culturales siga manteniendo una lógica propia.

\section{Bibliografía}

Alberdi, Juan Bautista (1955). Fragmento preliminar al estudio del derecho. Buenos Aires: Hachette.

Battista, María Valeria \& Judith Gociol (1992). "La traducción literaria carece de una legislación adecuada." Online en: http://www.lamaga.com.ar/www/area2/ar_numero_32.asp (consultado 10.07.2003).

Bein, Roberto (2001). "La teoría del polisistema, hoy: elementos vigentes y aspectos a revisar." De Babel a Internet: actas del III Congreso Latinoamericano de Traducción e Interpretación (tomo II). Buenos Aires: Colegio de Traductores Públicos de la Ciudad de Buenos Aires.

Blanco, Mercedes Isabel (1994). "Aspectos históricos e ideológicos de las actitudes lingüísticas en el Río de la Plata y Chile (1810-1850)." M. Fontanella de Weinberg (ed.) (1994). El español en el Nuevo Mundo: estudios sobre la historia lingüística hispanoamericana. Washington: O.E.A.

Casanova, Pascale (2001). La República de las letras (tr. Jaime Zulaika). Barcelona: Anagrama.

Even-Zohar, Itamar (1990a). "Polysystem Theory.” Poetics Today 11 (1), 9-26.

Even-Zohar, Itamar (1990b). "The position of Translated Literature within the Literary Polysystem." Poetics Today 11 (1), 45-51.

Even-Zohar, Itamar (1990c). "Laws of Literary Interference." Poetics Today 11(1), 53-72.

Fishman, Joshua (1972). Language and Nationalism. Massachussets: Newbury House.

Fontanella de Weinberg, María Beatriz (ed.) (1994) El español en el Nuevo Mundo: estudios sobre la historia lingüística hispanoamericana. Washington: O.E.A.

Gamerro, Carlos (2000). “Armar bardo.” Página 12, suplemento Radar libros, junio 11,3 .

Gutiérrez, Juan María (1977). "Fisonomía del saber español: Cuál deba ser entre nosotros." F. Weinberg (1977) El salón literario. Buenos Aires: Hachette.

Hyun, Theresa \& José Lambert (eds) (1995). Translation and Modernization. Vol. IV of Earl Miner and Haga Toru, General Eds, ICLA 91 Tokyo. The Force of Vision. Proceedings of the XIIIth Congress of the International Comparative Literature Association. Tokyo: University of Tokyo Press, 98-117.

Lambert, José (1989). “A la recherche de cartes mondiales des littératures.” J. Riesz \& A. Ricard (eds) (1989) Semper aliquod novi. Littérature comparée et littératures d'Afrique. Mélanges offerts à Albert Gérard. Tübingen: Narr, 109-21.

Lambert, José (1995). "Literatures, Translation and (De)Colonization." T. Hyun \& J. Lambert (eds) (1995). Translation and Modernization. Vol. IV of Earl Miner and Haga Toru, General Eds, ICLA 91 Tokyo. The Force of Vision. Proceedings of the XIIIth Congress of the International Comparative Literature Association. Tokyo: University of Tokyo Press, 98-117. 
Link, Daniel (2001). “Qué hay de nuevo, viejo?” Página 12, suplemento Radar Libros, octubre 14, 3.

Makovsky, Pablo (2002). "Para deleite del lector" (entrevista a Andrés Rivera). El ciudadano, junio 17, 12-13.

Minon, Marc \& Valéry Ganne (1992). "Géographie de la traduction." F. BarretDucrocq (ed.) (1992) Traduire l'Europe. Paris: Payot, 55-95.

Paker, Saliha (ed.) (2003). Proceedings of the International Conference Translation: (Re)shaping of Literature and Culture, Bogaziçi University, Estanbul. Online en: http://spinoza.tau.ac.il/ toury/works (consultado 12.07.2003).

Paz, Octavio (1994). Obras Completas. México: Fondo de Cultura Económica.

Riesz, János \& Alain Ricard (eds) (1989) Semper aliquod novi. Littérature comparée et littératures d'Afrique. Mélanges offerts a Albert Gérard. Tübingen: Narr, 109-21.

Sebreli, Juan José (2002). Crítica de las ideas argentinas. Buenos Aires: Sudamericana.

Toury, Guideon (en prensa). "Translation as a Means of Planning and the Planning of Translation: A Theoretical Framework and an Exemplary Case." Aparecerá en S. Paker (ed.). Proceedings of the International Conference Translation: (Re)shaping of Literature and Culture, Bogaziçi University, Estanbul. Online en: http://spinoza.tau.ac.il/ toury/works (consultado 12.07.2003).

Weinberg, Félix (1977). El salón literario. Buenos Aires: Hachette.

1 Dicho esto, emplearemos los términos sistema y polisistema indistintamente.

2 Según el filósofo Juan José Sebreli: "Junto al crecimiento económico [argentino, entre 1880 y 1930] se dio un desarrollo cultural que destacó al país del resto del continente. Hacia las primeras décadas del siglo XX, tanto la alta cultura como la industria cultural argentinas se difundían por todo el mundo hispanoparlante. Testimonio del esplendor de esa época quedó, casi como una ruina histórica, la ciudad de Buenos Aires [...] Jürgen Habermas la consideró una weltstadt; André Malraux la llamó "capital de un imperio que nunca existió" (2002: 14).

3 En el site chileno de Planeta (http://www.planeta.cl/), donde también se edita la Biblioteca del Sur, hemos encontrado una curiosa y elocuente declaración del proyecto, a título ilustrativo: "La Biblioteca del Sur, que inició sus publicaciones en 1989, ha sido la viga maestra en torno a la cual surgió y se desarrolló la Nueva Narrativa chilena" (el subrayado es nuestro).

${ }^{4}$ Hemos encontrado una formulación muy ilustrativa de este fenómeno en una entrevista realizada al escritor argentino Andrés Rivera, que por pudor reproducimos en nota final:

"Durante muchos años me interesó la literatura norteamericana y sobre todo el género policial, cuando estaba escrito por D. Hammett, R. Chandler, y después E. Hemingway, William Faulkner, que venían muy bien traducidos porque estaban traducidos por Borges, Cortázar, Enrique Pezzoni. Ahora traducen los españoles y es un horror: 'gilipollas', y 'vale'.

- Y 'follar'.

— Vamos a terminar nosotros diciendo follar. Hoy hay muy pocas editoriales argentinas, no pueden arriesgarse a traducir porque hay que pagar derechos. Estoy leyendo La mancha humana, de Philip Roth, está muy bien traducida, pero es inevitable que ponga 'tú me follaste' y, bueno, adiós" (Makovsky 2002).

5 El séptimo círculo, que Borges y Bioy Casares dirigieron desde 1945 hasta fines de los años cincuenta, fue la primera colección de literatura policial de habla hispana. 
6 Según Alberdi (1955: 81): "La lengua argentina no es, pues, una lengua española, como la nación argentina es hija de la nación española sin ser por eso la nación española. Una lengua es una facultad inherente a la personalidad de cada nación, y no puede haber identidad de lenguas, porque Dios no se plagia en la creación de las naciones".

7 En palabras de Juan María Gutiérrez (1977: 154), otro representante de la generación del 37, "Si hemos de tener una literatura, hagamos que sea nacional, que represente nuestras costumbres y nuestra naturaleza".

${ }_{8}$ Especialmente en Inquisiciones, El tamaño de mi esperanza y El idioma de los argentinos. Si bien el proyecto borgeano es ajeno a cualquier reivindicación folklórica, su rivalidad con la literatura y las instituciones académicas españolas requiere de una impugnación total del modelo de la vieja metrópolis. No olvidemos que el escritor matiza su gesto ("ni recaer en españoles ni degenerar en malevos"), y que luego renegará de los tres libros antes citados.

9 Es curioso constatar que en el momento en que el campo literario argentino da muestras de haber clausurado el debate acerca de la lengua nacional, el sistema literario hispanoamericano parece consolidarse a ojos de los promotores culturales de Sur, y la traducción literaria panhispánica se convierte en un objetivo de la planificación cultural, como atestigua la política de traducción de la revista.

${ }^{10}$ Casanova parece ignorar que, si bien la generación de la independencia en Argentina no desarrolló reivindicaciones lingüísticas y mantuvo una posición de purismo hacia la lengua española, la segunda generación fue claramente rupturista, para lo cual se basó en el modelo herderiano. Remito al artículo de Mercedes Blanco (1994), en el que desarrolla claramente este punto.

${ }^{11}$ Otro es el caso de la literatura especializada, ya sea científica, filosófica, ensayística o técnica. 